\title{
HESAPLAMALI AKIŞKAN DİNAMIĞİ İLE EKSENEL BİR ÇOCUK KALP DESTEK POMPASI PERFORMANSININ INCELENMESI
}

\author{
${ }^{1}$ Rafet YAPICI, ${ }^{2}$ Resul TEKE, ${ }^{3}$ Ömer İNCEBAY, ${ }^{4}$ Hasan ÇINAR* ${ }^{*}{ }^{5} \mathrm{Fehmi}$ MUTLU \\ 1,2,3,5Selçuk Üniversitesi, Mühendislik Fakültesi, Makine Müh. Bl. Selçuklu/Konya TÜRKIYYE \\ ${ }^{4}$ Gebze Teknik Üniversitesi, Makine Müh. Bl. Gebze/Kocaeli TÜRKIYE \\ 1rafet@selcuk.edu.tr, ${ }^{2}$ rsltk@yandex.com, ${ }^{3}$ oincebay@selcuk.edu.tr, ${ }^{4 h}$ hasancinar@gtu.edu.tr, \\ 5fhmmt192@gmail.com
}

(Geliş/Received: 07.04.2018; Kabul/Accepted in Revised Form: 13.05.2018)

ÖZ: Bu çalışmada, pompa tasarım programları kullanılarak eksenel akışlı bir çocuk kalp destek pompası

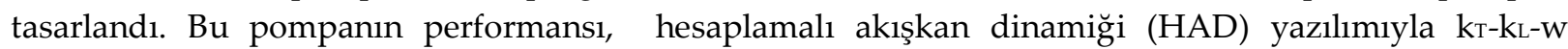
türbülans modeli kullanılarak belirlendi. Katı modeli oluşturulan pompanın gövdesi alüminyum bloktan CNC işleme tezgâhında imal edildi. Bu kalp destek pompasının çarkı, doğrultucusu ve difüzörünün 3D yazıcıyla imalatı yapıldı. Bu prototip pompanın, HAD simülasyonuyla belirlenen performans sonuçlarının deneysel doğrulaması, su ile yapıldı. Pompanın 9000-12000 dev/dak dönme sayısı aralığında, debisi 0.5-5 L/dak ve basınç farkı 35-95 mmHg arasında değişti. Kan benzeri akışkan için $2 \mathrm{~L} /$ dak tasarım debisi ve $80 \mathrm{~mm}-\mathrm{Hg}^{\prime}$ lik tasarım basıncı $11750 \mathrm{dev} / \mathrm{dak}$ dönme sayısında elde edildi. Çalışmanın sonunda, tasarım noktasında pompadaki cidar kayma gerilmeleri ve akış çizgileri incelendi.

Anahtar Kelimeler: Eksenel pompa, HAD, Kalp destek pompası, Pediatrik kalp destek pompası, PLVAD

\section{Investigation of Performance of an Axial Child Heart Assist Pump with Computational Fluid Dynamics}

\begin{abstract}
In this study, an axial flow child heart support pump was designed using pump design programs. The performance of this pump was determined using the $\mathrm{k}_{\mathrm{T}}-\mathrm{k}_{\mathrm{L}}-\mathrm{W}$ turbulence model with computational fluid dynamics (CFD) software. Body of this pump is manufactured from aluminum block with CNC machining center. The heart assist pump's impeller, straightener and diffuser were manufactured with 3D printers. Experimental verification of the performance results of this prototype pump determined by CFD simulation was made with water. In the range of $9000-12000 \mathrm{rpm}$ of the pump speed, the flow rate varied between 0.5-5 L/min while the pressure difference varied between 35-95 $\mathrm{mmHg}$. Design pressure of $80 \mathrm{mmHg}$ for design flow rate of $2 \mathrm{~L} / \mathrm{min}$ was achieved at $11750 \mathrm{rpm}$ for blood-like fluid. At the end of the work, the wall shear stresses and flow lines in the pump were examined at the design point.
\end{abstract}

Key Words:Axial pump, CFD, Heart Assist Pump, Pediatric Ventricular Assist Pump , PLVAD

\section{GíRİ̧̧ (INTRODUCTION)}

2012 yılında dünyada yaklaşık 56 milyon ölüm meydana gelmiştir. Bu ölümlerin 38 milyonu Bulaşıcı Olmayan Hastalıklara (BOH) özellikle kalp ve damar hastalıkları, kanser, kronik hava yolu hastalıklarına bağlı ölümlerdir (Bakanlık, 2015). BOH'lar içerisinde, kalp ve damar hastalıkları tüm ölüm nedenleri arasında ilk sırada yer almaktadır. Kalp ve damar hastalıklarının uzun bir süre daha bir numaralı ölüm sebebi olacağı tahmin edilmektedir. Ayrıca yapılan araştırmalarda ülkemizde, yaklaşık 
olarak yılda 1,3 milyon bebek doğduğu göz önüne alındığında, her yıl yeni doğan bebeklerden 13 bininin doğuştan kalp hastalığı ve bunlardan da 3.3 bininin kritik kalp hastalığ 1 ile aramıza katıldığ söylenebilir. Ülkemize paralel olarak Amerika Birleşik Devletleri'nde, her 100 bebekten birinin kalp rahatsızlığının olduğu ve cerrahi müdahalede bulunulan \%85'inin yetişkin çağa eriştiği tespit edilmiştir (Warnes, 2005). Yine Amerika Birleşik Devletleri'nde yıllık donor sayısı ortalama 500 civarındadır (B Clark ve diğ., 2011).Toplumların yaşlanması ve beklenen yaşam süresinde görülen uzama ile gelişmiş ülkelerde kalp ve damar hastalarının sayısı artmakta ve bunlara bağlı yük de artmaktadır. BOH'ların oluşturduğu hastalık yükünde önemli bir payı olan kalp ve damar hastalıkları açısından olumlu olan husus büyük ölçüde "önlenebilir" olmalarıdır (Bakanlık, 2015). Bu alanda birçok çalışma yapılmaktadır, bu çalışmalardan biride kalp destek sistemleridir.

Sol karıncık kalp destek cihazı, kalp yetmezliği olan hastalarda destek ve tedavi amacıyla kullanılmaktadır. Destek tedavisi, özellikle kalp transplantasyonu bekleyen hastalarda bekleme süresini uzatmayı amaçlamaktadır. Yapay kalp destek cihazları, vücut içine yerleştirilen (implantable, minyatür) ve vücut dişında (parakorporal) olan olmak üzere iki farklı gruptur. Hangisinin takılacağı, hastanın kalp yetersizliğinin ve genel durumunun özelliklerine göre belirlenir. Kalbin sol ventrikülünden (karıncık) alınan kan, bir pompa vasıtası ile ana atardamar olan aorta gönderilir ve bu kalp yetmezliği olan hastalarda kan dolaşımının tekrar normal miktarlara gelmesini sağlanır. Ancak bu pompaların kullanımında pek çok sorunla karşılaşılabilmektedir. Bu sorunların başında pompa içinde meydana yüksek kayma gerilmeleri sonucu kan hücrelerinin deformasyona uğraması ve bunun sonucunda hemoliz meydana gelmesidir (Reul ve Akdis, 2000). Pompa tasarımları yapılırken hemoliz indeksi oranını en aza indirgeyecek tasarımlar yapılmalıdır.

Hesaplamalı akışkanlar dinamiği (HAD) simülasyonu, çeşitli akış makine ve cihazlarında yaygın olarak kullanılan ileri bir araştırma, geliştirme ve tasarım tekniğidir. HAD simülasyon yazılımları sayesinde pompanın üretilmeden ve denenmeden tasarım aşamasında performansları tahmin edilerek hedeflenen amaca göre pompa üzerinde modifikasyonlar gerçekleştirilebilmektedir

$\mathrm{Bu}$ çalışmanın birinci amacı; ANSYS 18.0 yazılımı kullanılarak tasarlanan pompanın üretilmeden önce HAD simülasyonları yardımıyla hidrolik performansını belirleyip ondan sonra prototipinin üretilmesi ve daha sonra deneyler yapılarak sonuçların karşılaştırılmasıdır. İkinci amacı ise deneysel doğrulamadan sonra, bu çocuk kalp destek pompasının performansını boyutsuz parametrelere göre belirlemektir.

\section{MATERYAL VE METOD (MATERIAL and METHOD)}

Baldwin ve diğ. (2011) yapmış olduğu çalışmada; çocuk kalp destek pompası 2 L/dak tasarım debisinde $80 \mathrm{mmHg}$ basınç verecek şekilde tasarlanmıştır. Bu çalışmada da $2 \mathrm{~L} /$ dak tasarım debisi ve 80 mmHg tasarım basıncı için Pediatrik Sol Karıncık Kalp Destek Pompası (PLVAD) Ansys BladeGen programı kullanılarak tasarlandı. Bu parametreler üzerinden gövde çapı (dolayısıyla kanat ucu çapları) sabit olan eksenel pompanın doğrultucusu, difüzörü ve çarkı Ansys BladeGen programı ile tasarlandı. Boyutları belirlenen bu pompanın CAD programlarıyla katı modeli oluşturuldu. Bu model üzerinden ticari bir HAD yazılımı olan ANSYS Fluent 18.0 programı ile pompanın sayısal simülasyon analizleri yapıldı. Deney ve simülasyon için çalışma (test) aralığı olarak 0.5-5 L/dak debi ve 9000-12000 dev/dak dönme sayısı seçildi. Analizler sonrasında pompanın katı modeline uygun olarak çark, difüzör ve doğrultucu imal edildi. İmal edilen pompanın parçaları Şekil 2'de gösterilmiştir. HAD simülasyonlarının deneysel doğrulamasını yapmak için deney seti kurularak imal edilen prototip pompanın deneysel performansı belirlendi ve sayısal sonuçlar ile deneysel sonuçlar karşılaştırıldı. Deneysel doğrulamadan sonra belirtilen çalışma aralığında pompanın boyutsuz parametrelere bağlı olarak performansı belirlendi. 


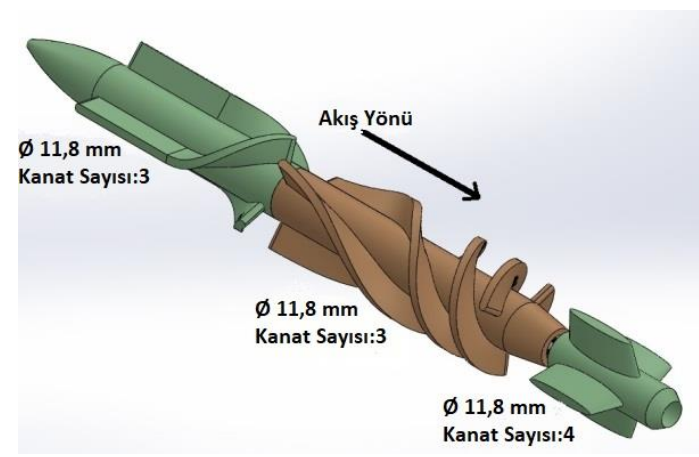

Şekil 1. Oluşturulan katı model

Figure 1. Created solid model

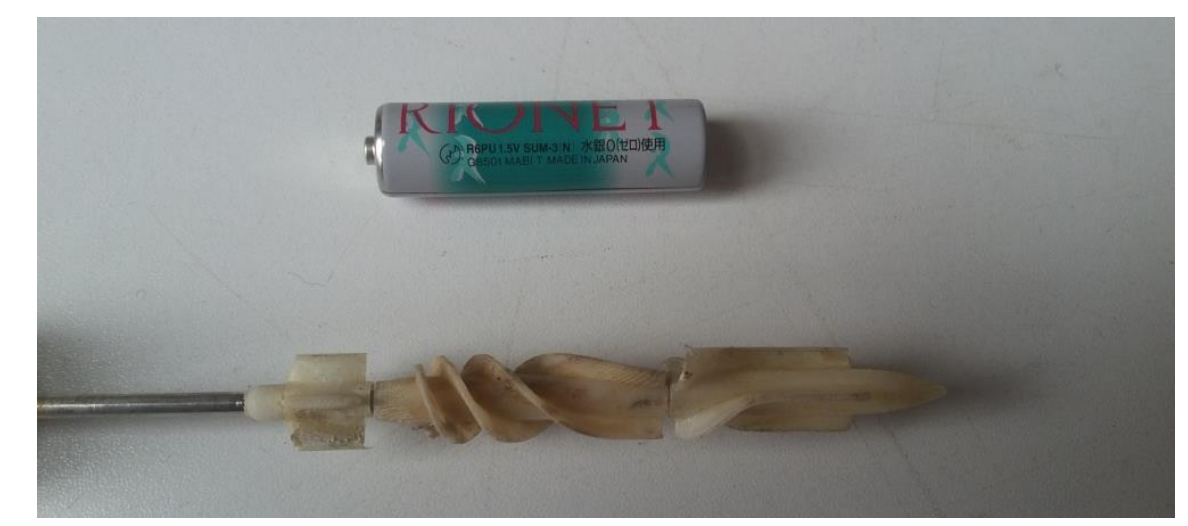

Şekil 2. Pompa doğrultucusu (soldaki), çarkı (ortadaki) ve difüzörü (sağdaki)

Figure 2. The pump straightener(left), impeller(center) and diffuser(right)

\section{HAD Simülasyonu (CFD Simulation)}

Eksenel akışlı pediatrik VAD'larda Reynolds sayısı $10^{4}$ mertebesinde olduğu zaman akışta türbülansın egemen olduğu kabul edilir (Throckmorton ve Untaroiu, 2008). Rotodinamik (çarklı) pompalarda bu sayı $\mathrm{Re}=\rho \omega \mathrm{D}^{2} / \mu$ ifadesiyle tanımlanır. Bu çalışmadaki kullanılan debi ve dönme sayısının alt ve üst sınırlarında su ve kana benzer akışkan için Reynolds sayısı değerleri Tablo 1'de verilmiştir.

Tablo 1. Pompadaki Reynolds sayısı değerleri

Table 1. Reynolds number values in the pump

\begin{tabular}{|l|llll|}
\hline Akışkan & $\begin{array}{l}\text { Çark } \\
\mathbf{N}=\mathbf{9 0 0 0} \text { dev/dak }\end{array}$ & $\begin{array}{l}\text { Çark } \\
\mathbf{N}=\mathbf{1 1 7 5 0} \text { dev/dak }\end{array}$ & $\begin{array}{l}\text { Borular } \\
\mathbf{Q}=\mathbf{0 . 5} \mathbf{~ L / d a k}\end{array}$ & $\begin{array}{l}\text { Borular } \\
\mathbf{Q}=\mathbf{5} \mathbf{~} / \text { dak }\end{array}$ \\
\hline Su & $1.3 \times 10^{5}$ & $1.7 \times 10^{5}$ & $1 \times 10^{3}$ & $1 \times 10^{4}$ \\
Kan benzeri & $3.7 \times 10^{4}$ & $4.9 \times 10^{4}$ & $2.9 \times 10^{2}$ & $2.9 \times 10^{3}$ \\
\hline
\end{tabular}

Bu çalışmada, bu tipteki yüksek hızlı pompa için yakınsayan ve daha doğru çözümler verdiği için

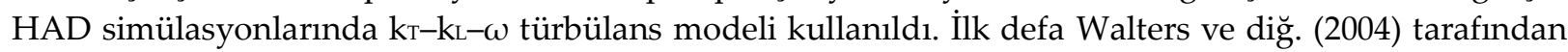
önerilen bu model daha sonra, yine Walters ve diğg. (2008) tarafından modifiye edilmiştir. Bu model, esasında $\mathrm{k}-\omega$ modeline dayanır. $\mathrm{k}-\omega$ modelinden farklı olarak laminar kinetik enerji biçimindeki yüksek frekanslı akış dalgalanmalarının etkilerini hesaba katan ilave bir transport denklemine ( $\mathrm{k}$ ) sahiptir ve geçiş bir modelidir.

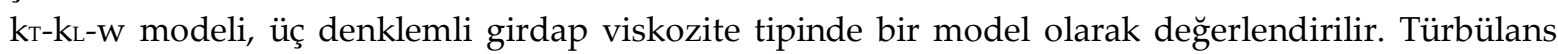
kinetik enerjisi $\left(\mathrm{k}_{\mathrm{T}}\right)$, laminer kinetik enerji $\left(\mathrm{kL}_{\mathrm{L}}\right)$ ve ters türbülans zaman ölçeğine $(\omega=\varepsilon / k T)$ ait denklemleri içerir. Sıkıştırılamaz akış için bu model denklemleri aşağıdaki gibidir: 


$$
\begin{aligned}
& \frac{D k_{T}}{D t}=P_{k_{T}}+R_{B P}+R_{N A T}-\omega k_{T}-D_{T}+\frac{\partial}{\partial x_{j}}\left[\left(v+\frac{\alpha_{T}}{\alpha_{k}}\right) \frac{\partial k_{T}}{\partial x_{j}}\right] \\
& \frac{D k_{L}}{D t}=P_{k_{L}}-R_{B P}-R_{N A T}-D_{L}+\frac{\partial}{\partial x_{j}}\left[v \frac{\partial k_{L}}{\partial x_{j}}\right] \\
& \frac{D \omega}{D t}=C_{\omega 1} \frac{\omega}{k_{T}} P_{k_{T}}+\left(\frac{C_{\omega R}}{f_{W}}-1\right) \frac{\omega}{k_{T}}\left(R_{B P}+R_{N A T}\right)-C_{\omega 2} \omega^{2} f_{W}^{2} \\
& +C_{\omega 3} f_{\omega} \alpha_{T} f_{W}^{2} \frac{\sqrt{k_{T}}}{d^{3}}+\frac{\partial}{\partial x_{j}}\left[\left(v+\frac{\alpha_{T}}{\alpha_{\omega}}\right) \frac{\partial \omega}{\partial x_{j}}\right]
\end{aligned}
$$

Türbülans ve laminer dalgalanmaların, girdap viskozitesi ve termal difüzivite yoluyla ortalama akış ve enerji denklemlerine katılması aşağıdaki gibidir.

$$
\overline{-u_{i} u_{j}}=v_{T O T}\left(\frac{\partial U_{i}}{\partial x_{j}}+\frac{\partial U_{j}}{\partial x_{i}}\right)-\frac{2}{3} k_{T O T} \delta_{i j} ; \quad \overline{-u_{i} \theta}=\alpha_{\theta, T O T} \frac{\partial \theta}{\partial x_{i}}
$$

Efektif uzunluk ve uzunluk ölçeği $\lambda \mathrm{T}$, şöyle tanımlanır:

$$
\lambda_{\text {eff }}=\min \left(C_{\lambda} d, \lambda_{T}\right) ; \quad \lambda_{T}=\frac{\sqrt{k_{T}}}{\omega}
$$

Burada d cidara olan mesafedir. Küçük ölçekli türbülans enerjisi şöyle tanımlanır:

$$
k_{T, s}=f_{s s} f_{W} k_{T} ; \quad f_{W}=\left(\frac{\lambda_{e f f}}{\lambda_{T}}\right)^{2 / 3} ; \quad f_{s s}=\exp \left[-\left(\frac{C_{s s} r \Omega}{k_{T}}\right)^{2}\right]
$$

Büyük ölçek enerjisi şöyle verilir:

$$
k_{T, l}=k_{T}-k_{T, s}
$$

Denklem (6)'daki ilk ifade ile Denklem (7)'nin toplamı türbülans kinetik enerjisini (kт) verir. Türbülans dalgalanmaları tarafından oluşturulan türbülans üretimi terimi şöyle verilir:

$$
P_{k_{T}}=v_{T, S} S^{2}
$$

Buradaki $S=\left(S_{\mathrm{ij}} \mathrm{S}_{\mathrm{ij}}\right)^{1 / 2}$ ve $v_{\mathrm{T}, \mathrm{s}}$ küçük ölçekli türbülans viskozitesidir:

$$
v_{T, s}=f_{v} f_{I N T} C_{\mu} \sqrt{k_{T, s}} \lambda_{e f f} ; \quad C_{\mu}=\frac{1}{A_{0}+A_{s}(S / \omega)} ; \quad f_{v}=1-\exp \left(-\frac{\sqrt{\operatorname{Re}_{T, s}}}{A_{v}}\right)
$$

Kesiklikten dolayı türbülans üretimini tanımlayan sönümleme fonksiyonu şöyle verilir:

$$
f_{I N T}=\min \left(\frac{k_{T}}{C_{I N T} k_{T O T}}, 1\right) ; \quad \operatorname{Re}_{T, s}=\frac{f_{W}^{2} k_{T}}{v \omega}
$$

Denklem (2)'deki $P_{k L}$, büyük ölçekli türbülans dalgalanmalarından dolayı laminer kinetik enerji üretimidir.

$$
P_{k_{L}}=v_{T, l} S^{2}
$$

Büyük ölçekli türbülans viskozitesi şöyle modellenir: 
$v_{T, l}=\min \left\{v_{T, l}^{*}, \frac{0.5\left(k_{L}+k_{T, l}\right)}{S}\right\} ; \quad v_{T, l}^{*}=f_{\tau, l} C_{11}\left(\frac{\Omega \lambda_{e f f}^{2}}{l}\right) \sqrt{k_{T, l}} \lambda_{e f f}+\beta_{T S} C_{12} \varphi_{N A T} d^{2} \Omega$

Denklem (12)'deki limit, gelişen iki boyutlu akışta bu denklemin (aykırı olmamasını) uygun olmasını sağlar. Zaman ölçeği bazlı sönümleme fonksiyonu $\mathrm{f}_{\tau, 1}$ ve Denklem (12)'deki ikinci ifadedeki diğer iki terim:

$f_{\tau, l}=1-\exp \left(-C_{\tau, l} \frac{k_{T, l}}{\lambda_{e f f}^{2} \Omega^{2}}\right) ; \beta_{T S}=1-\exp \left(-\frac{\max \left(\varphi_{N A T}-C_{T S, c r i t}, 0\right)^{2}}{A_{T S}}\right) ; \varphi_{N A T}=\frac{d^{2} \Omega}{v}$

Cidar yakınındaki kayıplar şöyle verilir:

$D_{T}=2 v \frac{\partial \sqrt{k_{T}}}{\partial x_{j}} \frac{\partial \sqrt{k_{T}}}{\partial x_{j}} ; \quad D_{L}=2 v \frac{\partial \sqrt{k_{L}}}{\partial x_{j}} \frac{\partial \sqrt{k_{L}}}{\partial x_{j}}$

Denklem (1) ve (2)'deki $R$, bypass geçişi sırasında akış yönündeki dalgalanmaların türbülansa dönüşmesinin ortalama etkisini gösterir:

$R_{B P}=\frac{C_{R} \beta_{B P} k_{L} \omega}{f_{W}} ; \quad \beta_{B P}=1-\exp \left(-\frac{\varphi_{B P}}{A_{B P}}\right) ; \quad \varphi_{B P}=\max \left[\left(\frac{k_{T}}{\nu}-C_{B P, c r i t}\right), 0\right]$

Buradaki $\beta_{\mathrm{BP}}$, bypas geçiş işlemini kontrol eden eşik fonksiyonudur.

Kararsızlıklardan dolayı türbülans oluşması, doğal geçiş üretim terimi olarak dikkate alını:

$$
\begin{aligned}
& R_{N A T}=C_{R, N A T} \beta_{N A T} k_{L} \Omega ; \beta_{N A T}=1-\exp \left[-\frac{\max \left(\varphi_{N A T}-C_{N A T, c r i t} / f_{N A T, c r i t}, 0\right)}{A_{N A T}}\right] ; \\
& f_{N A T, \text { crit }}=1-\exp \left(C_{N C} \frac{\sqrt{k_{L}} d}{v}\right)
\end{aligned}
$$

Ölçek belirleme değişkeni olarak $\omega^{\prime}$ nin kullanılması, türbülans sınır tabakasının dış bölgesinde azalan bir kesiklik etkisine yol açar ve sonuçta hız profilinde iz bölgesi yok olur. Denklem (3)'den, aşağıdaki sönümleme fonksiyonu tanımlanır:

$$
f_{\omega}=1-\exp \left[-0.41\left(\frac{\lambda_{\text {eff }}}{\lambda_{T}}\right)^{4}\right]
$$

Denklem (9) ve (12)'de görülen toplam girdap viskozitesi ve girdap difüzivitesi şöyle verilir:

$$
v_{T O T}=v_{T, s}+v_{T, l} ; \quad \alpha_{\theta, T O T}=f_{W}\left(\frac{k_{T}}{k_{T O T}}\right) \frac{v_{T, s}}{\operatorname{Pr}_{\theta}}+\left(1-f_{W}\right) C_{\alpha, \theta} \sqrt{k_{T}} \lambda_{\text {eff }}
$$

Denklem (1) ve (3)'deki türbülans skaler difüzzivitesi şöyle tanımlanır:

$$
\alpha_{T}=f_{v} C_{\mu, s t d} \sqrt{k_{T, s}} \lambda_{e f f} ; \quad k_{T O T}=k_{T}+k_{L}
$$

Bu modelin sabitleri (A, C, Pr ve $\sigma$ ile gösterilen) ANSYS Fluent Theory Guide 18.0 sürümünde listelenmiştir (Fluent, 2017). Bu model, Walters ve diğ. (2008) tarafından daha detaylı olarak anlatılmıştır. Füsrt ve diğ.(2013), laminerden türbülanslı akışa geçişi dikkate olan birkaç modeli kıyaslamıştır. Yazarlar, kT-kL- $\omega$ modelinin, düz levha üzerindeki testlerde serbest akış türbülansının etkisini , $\gamma$-Re e $_{\theta}$ geçiş modelinden daha iyi tahmin ettiğini ifade etmişlerdir. 
HAD simülasyonu için pompa çarkının hareketli, doğrultucu ve difüzörün sabit olacağı bir blok içine yerleştirilen bir model hazırlanıp (Şekil 3), model içindeki akış alanı için Fine 100 mertebesinde bir çözüm ağı oluşturuldu. İlk çözüm ağı üzerinden ön analizler yapıldı ve ardından $\mathrm{y}^{+}$yüzey hücre iyileştirmesi yapılarak çözüm ağı geliştirildi. Analizlerde hesaplanan sonucun, çözüm ağındaki düğüm sayısına bağlılığının tespiti için 11000 dev/dak dönme sayısında $2 \mathrm{~L} /$ dak tasarım debisinde farklı çözüm ağı sayılarında analizler yapılıp yaklaşık 3.7 milyon adet hücre ile kararlı bir sonuca ulaşılabildi.

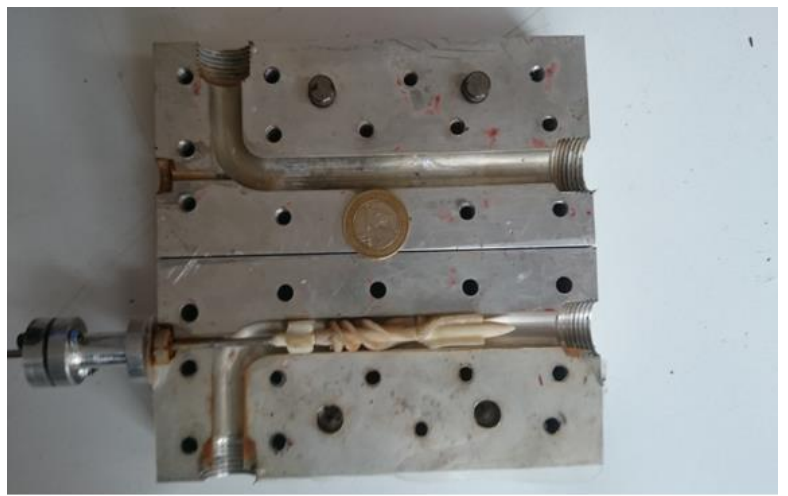

Şekil 3. Pompanın genel görünümü (Üst gövdesi çıkarılmış durumda) Figure 3. General view of the pump (Upper body removed)

Bu çözüm ağ1 üzerinden kT-kL-w türbülans modeli kullanılarak 9000-12000 dev/dak aralığındaki dört farklı dönme sayısında 0.5-5 L/dak arasında 6 noktadaki debi için çözümler yapıldı. Basınç bazlı çözücüde yöneten denklemleri (süreklilik ve momentum) ve türbülans modeli denklemleri ikinci mertebeden doğruluktaki ayrıklaştırma şemaları kullanılarak çözüldü. Fluent çözümlerinde yakınsama kriteri $10^{-4}$ olarak belirlendi. Deneysel doğrulamada akışkan olarak su ve HAD simülasyonlarında kana eşdeğer viskozite $\left(3.5 \times 10^{-5} \mathrm{~kg} / \mathrm{m} . \mathrm{s}\right)$ ve yoğunluktaki $\left(1050 \mathrm{~kg} / \mathrm{m}^{3}\right)$ sıvı kullanıldı. Pompaya giriş ve çıkışlarda türbülans şiddeti $T S ̧=0.16 \mathrm{Re}^{-1 / 8}$ ifadesiyle tanımlandı. Pompa performansının tespitinde kullanılan parametrelerden:

Pompa yükü, akışkanın pompada özgül enerjisindeki artıştır;

$\mathrm{H}=\frac{\Delta \mathrm{P}_{\mathrm{t}}}{\gamma}=\frac{\mathrm{P}_{\mathrm{tc}}-\mathrm{P}_{\mathrm{tg}}}{\gamma}$

Buradaki toplam basınç, akışkanı statik basıncıyla dinamik basıncının toplamıdır;

$\frac{\mathrm{P}_{\mathrm{t}}}{\gamma}=\frac{\mathrm{P}}{\gamma}+\frac{\mathrm{V}^{2}}{2 \mathrm{~g}}$

Akışkan gücü, birim zamanda akışkan üzerine çarkın yaptı̆̆ iştir;

$\mathrm{N}_{\mathrm{a}}=\gamma \mathrm{QH}$

Pompa gücü, çartaki tork ile açısal hızı çarpımıdır;

$\mathrm{N}_{\mathrm{p}}=\mathrm{T} \omega$

Pompa hidrolik verimi;

$\eta_{h}=\frac{N_{a}}{N_{p}}$ 


\section{Deneysel Yöntem (Experimental Method)}

Pompa tasarım programları kullanılarak katı modeli oluşturulan pompanın gövdesi dışındaki kanatlı elemanları 3D yazıcı (FDM Tekniği) yardımıyla PLA (Polilaktik Asit Termoplastik Polyester) malzemeden üretildi. Pompa gövdesinin imalat malzemesi olarak paslanmaz olması ve kolay işlenebilmesi açısından alüminyum malzeme tercih edildi. Bu gövde, CNC dik işlem tezgâhı ile alüminyum blok üzerine işlenerek imal edildi. Pompa mili $3 \mathrm{~mm}$ çapında paslanmaz çelik malzemeden imal edildi. Mil ile gövde arasındaki sızdırmazlığı sağlamak için grafitli-örgülü tipli salmastra kutusu kullanıldı. Mili yataklamak için kapaklı 603 rulman kullanıldı. HAD simülasyon sonuçlarını doğrulamak ve bu pompanın gerçek performansını belirlemek için kurulan deney düzeneğinin şematik gösterimi Şekil 4'de verilmiştir.

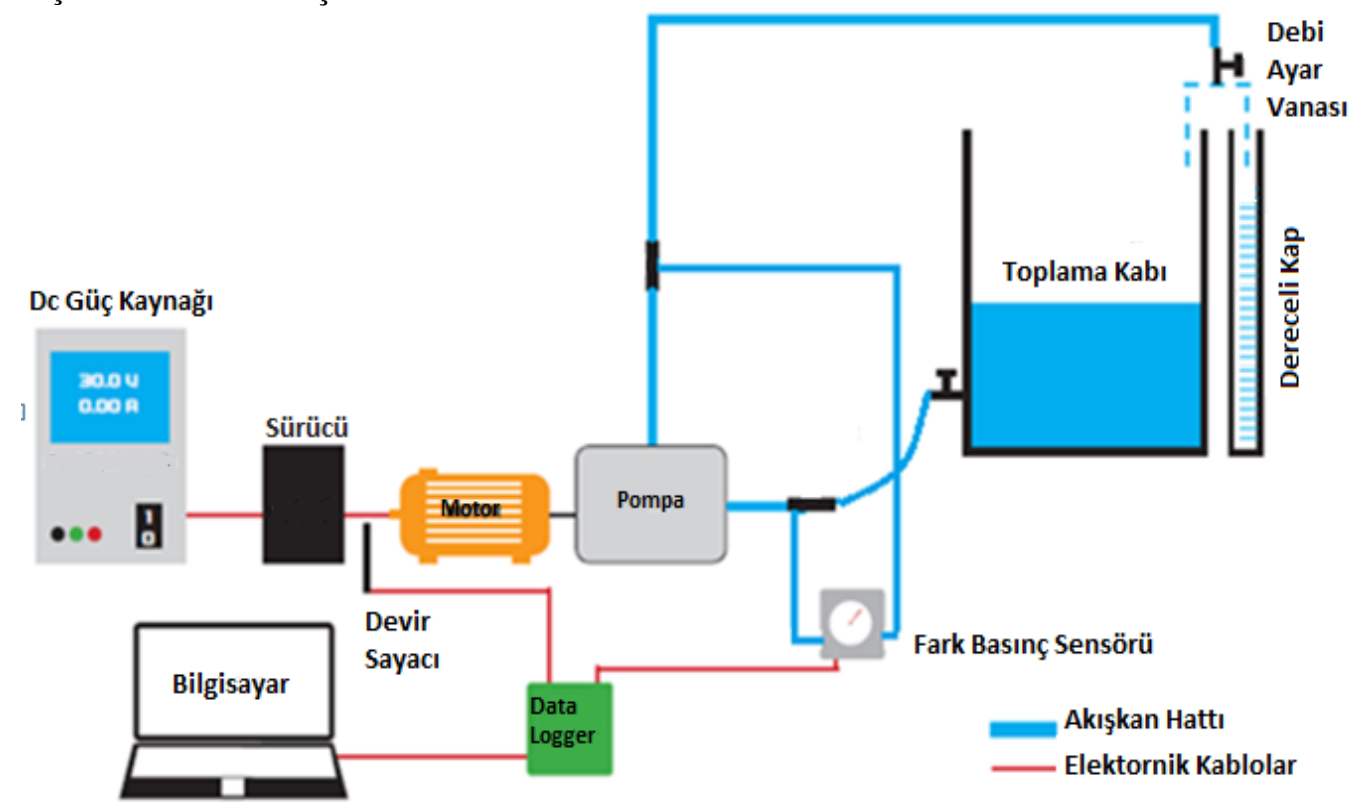

Şekil 4. Deney düzeneğinin şematik gösterimi

Figure 4. Schematic representation of the test setup

Deney akışkanı suyun içinde bulunduğu ağzı atmosfere açık toplama kabı, $10.5 \mathrm{~mm}$ iç çapa sahip olan esnek hortumlarla pompaya bağlanmıştır. Pompa çıkışındaki su, tekrar aynı tip esnek hortumlarla bu kaba geri pompalandı. Basma hattına debi ayarı yapmak için bir vana konuldu. Debi ölçümü için dereceli kaba akışkanı yönlendirmek amacıyla debi ayar vanasından sonra esnek bir hortum yerleştirildi. Hortumun yönü değiştirilerek akışkan dereceli kaba yönlendirildi. Deneyde debi, hacmi bilinen bir kap ile suyun hacmi bir kronometreyle suyun alınma zamanı ölçülerek belirlendi.

Pompanın emme ve basma hatlarındaki şeffaf plastik borular üzerlerine basınç ölçümlerinin yapılacağı $2 \mathrm{~mm}$ çapında delikler delinerek, bu deliklere çok küçük çaplı basınç sinyal hortumları takıldı, bu hortumlarla basınç sinyali fark basınç sensörüne iletildi. Basınç ölçümü için \% 0.25 hassasiyete sahip Valcom 27D Fark basınç sensörü kullanıldı. Fark basınç sensörünün doğrulaması civalı U tipi manometre ile yapıldı. Motor devir sayısının ölçümü ise motor-pompa mili bağlantısı üzerine takılan bir endüktif proximity sensörüyle yapıldı. Deneyde motor devir sayacı olarak Sick IME1603 endüktif proximity sensör kullanıldı. Bu sayacın doğruluğunun kontrolü \%0.05 hassasiyete sahip Lutron DT2236 dijital foto takometre ile yapıldı.

Simülasyon sonuçlarını doğrulama deneylerinde akışkan olarak su kullanıldı. 9000 den 11750 dev/dak arasında değişen pompa hızlarında 0.5-5 L/dak debi aralığında 6 farklı noktada ölçümler yapıldı. Bir debideki deney en az üç kez tekrarlanıp ortalama değerlerle bu kalp destek pompasının performans eğrileri çizildi. 


\section{HAD Sonuçların Deneysel Olarak Doğrulanması (Experimental Verification of CFD Results)}

Hesaplamalı akışkanlar dinamiği simülasyonuyla elde edilen çocuk kalp destek pompası $H=f(Q)$ performansının, akışkan olarak su kullanılan deneylerle doğrulanmasını gösteren sonuçlar Şekil 5'de verilmiştir. Burada incelenen eksenel pompanın hem sayısal hem de deneysel debiye göre pompa yükünün (basıncının) değişimi, yüksek özgül hızlı büyük ölçekli rotodinamik (çarklı) pompalarınkine benzer bir davranış göstermektedir. Suyla yapılan deneylerin sonuçlarının, HAD yazılımıyla elde edilen sonuçlarla benzerlik gösterdiği tespit edilmiştir. Tasarlanan pompanın tasarım noktasında ( $2 \mathrm{~L} / \mathrm{dak}$ debi, $80 \mathrm{mmHg}$ ve $11750 \mathrm{dev} / \mathrm{dak}$ ) su için deney ve HAD arasında yaklaşı \%2,5 sapma olduğu görülmüştür. Demir ve diğ. (2011) Yapmış olduğu çalışmada; tasarım noktasında, akışkanın su olduğu durumda, deney ile simülasyon arasında \%9 sapma olmuştur. Aka ve diğ. (2014) Yaptığı çalışmada; tasarım noktasında deney ile HAD simülasyonu arasındaki sapma yaklaşık \%14,5 olmuştur. Bu çalışmada elde edilen \%2.5'lik sapma değeri literatürdeki benzer çalışmalarla kıyaslandığ zaman kabul edilebilir bir değerdir. Böylece HAD simülasyonu, deneyle doğrulanmıştır. 4 L/dak'dan yüksek debilerde, simülasyon ve deneysel pompa yükleri (basınçları) arasındaki farkların tüm devir sayılarındakinden biraz daha fazla olduğu görülmüştür. 0-5 L/dak aralığında pompa basıncı yaklaşık 35 ila $95 \mathrm{mmHg}$ arasında değişmektedir.

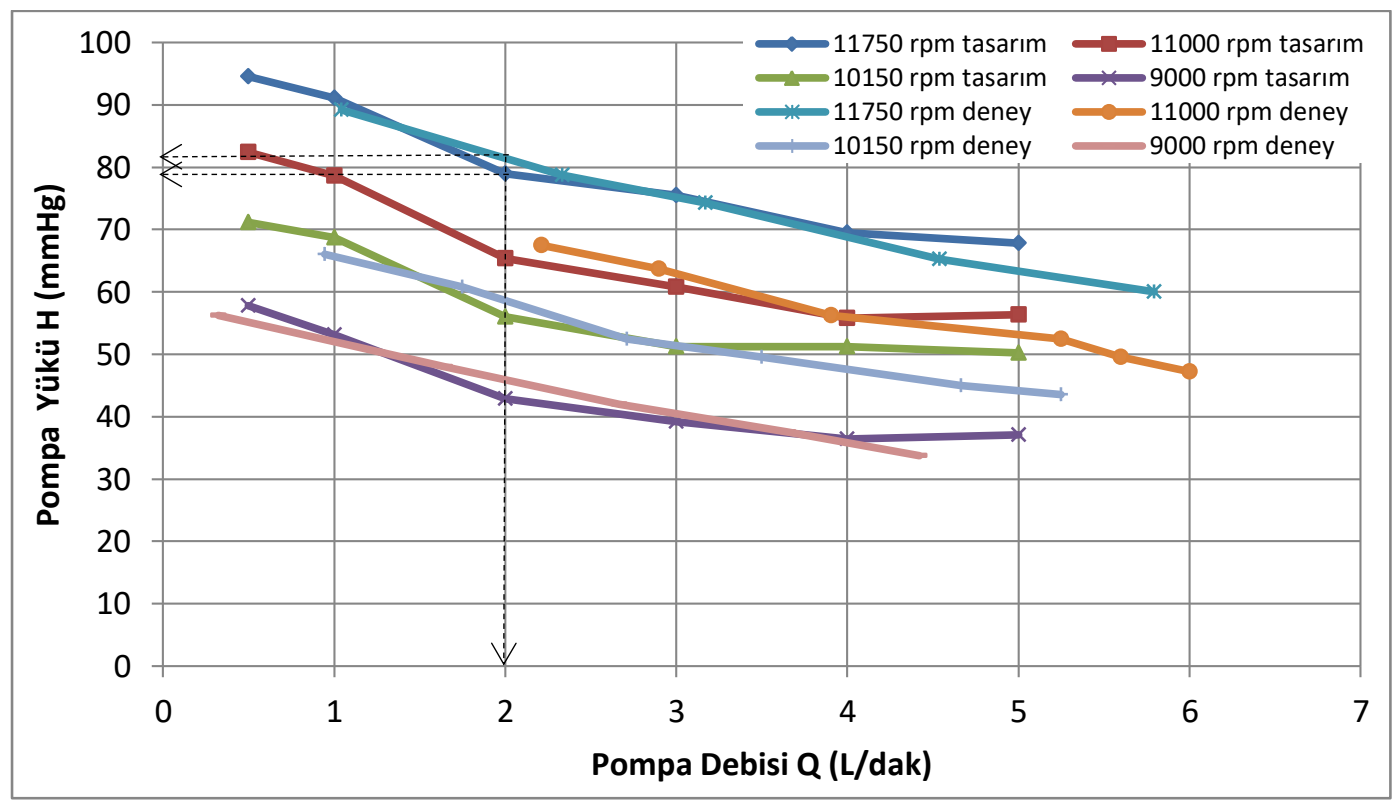

Şekil 5. HAD sonuçlarının deneysel sonuçlarla doğrulanması Figure 5. Verification of CFD results with experimental results

\section{SONUÇLAR VE TARTIŞMA(RESULTS AND DISCUSSION)}

Pompanın HAD analizi veya deneysel sonuçlarının daha az sayıda parametre ile ifade edilebilmesi ve genelleştirilebilmesi için; onların hidrodinamik performans eğrileri, basınç ve debi katsayısı gibi boyutsuz parametreler kullanılarak gösterilir. Boyutsuz parametreler yardımıyla gösterim metodu Kafagy ve diğ. (2015) ve Wu ve diğ. (2001),(2012) gibi araştırmacıların çalışmalarında da kullanıldığı görüldü. Pompanın iki temel boyutsuz hidrodinamik parametresinden basınç katsayısı $(\psi)$ ve debi katsayısının $(\Phi)$, boyutsuz ifadeleri aşağıda sırayla verilmiştir.

$$
\begin{gathered}
\psi=\left(\frac{\Delta P}{\rho N^{2} R^{2}}\right) \\
\Phi=\left(\frac{Q}{N R^{3}}\right)
\end{gathered}
$$


Burada Q debiyi ( $\left.\mathrm{m}^{3} / \mathrm{s}\right), \mathrm{N}$ çarkın dönme hızını (1/s), $\mathrm{R}$ çark yarıçapını $(\mathrm{m}), \Delta \mathrm{P}_{\mathrm{t}}=\gamma \mathrm{H}$ pompa basıncını $\left(\mathrm{kg} \cdot \mathrm{m} / \mathrm{s}^{2} \mathrm{~m}^{2}\right)$ ve $\rho$ akışkan yoğunluğunu $\left(\mathrm{kg} / \mathrm{m}^{3}\right)$ göstermektedir. (25) ve (26) numaralı formüllerle hesaplanan boyutsuz parametrelerle çizilen debi-basınç grafiği Şekil 6'da gösterilmiştir. Pompa çark çapının $12 \mathrm{~mm}$ olduğu bu çalışmada tasarım noktası değerleri $\mathrm{Q}=2 \mathrm{~L} /$ dak ve $\mathrm{H}=80 \mathrm{mmHg}$ için sırayla boyutsuz debi katsayısı $\Phi_{\text {den }} \cong 0.15$ ve pompa yük (basınç) katsayısı $\psi$ den $\cong 0.19^{\prime}$ dur. Throckmorton ve diğg. (2007) tarafından yapılan araştırmada aynı deneysel debi katsayısında $\psi$ den $\cong 0.185$ olarak bulunmuştur. $\mathrm{Bu}$ araştırmada pompa gövdesi içinde eksenel akış sağlayan pompa çarkının çapı 14 mm'dir.

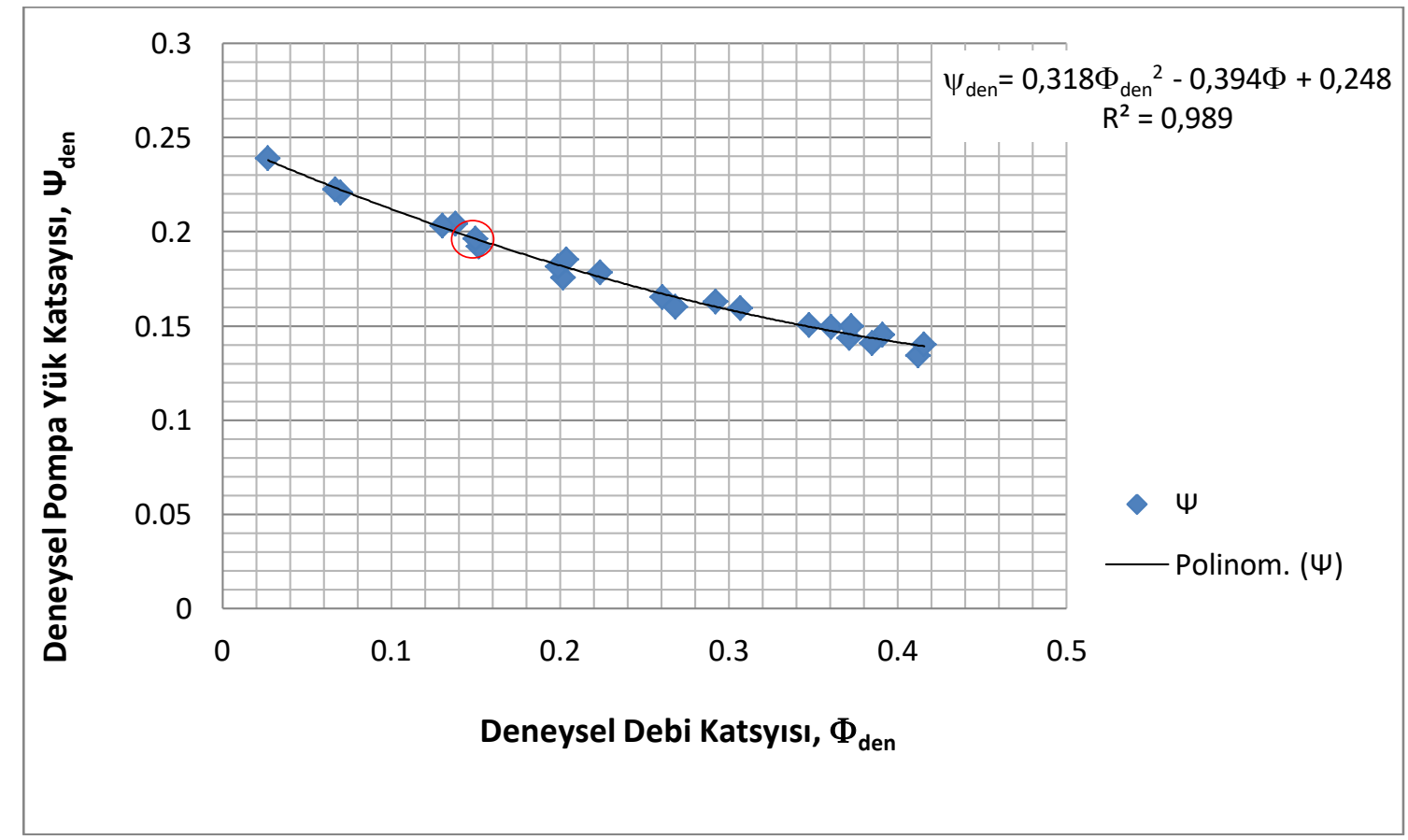

Şekil 6. Su için boyutsuz parametrelere göre deneysel performans eğrisi

Figure 6. Experimental performance curve according to dimensionless parameters for water

$\mathrm{R}^{2}=0.989$ değerine göre $\psi_{\text {den }}$ ve $\Phi_{\text {den }}$ arasında ikinci derecen bir kuvvetli bağıntı olduğu açıktır. Benzer durum, Şekil 7'deki HAD simülasyon sonuçları için de geçerlidir.

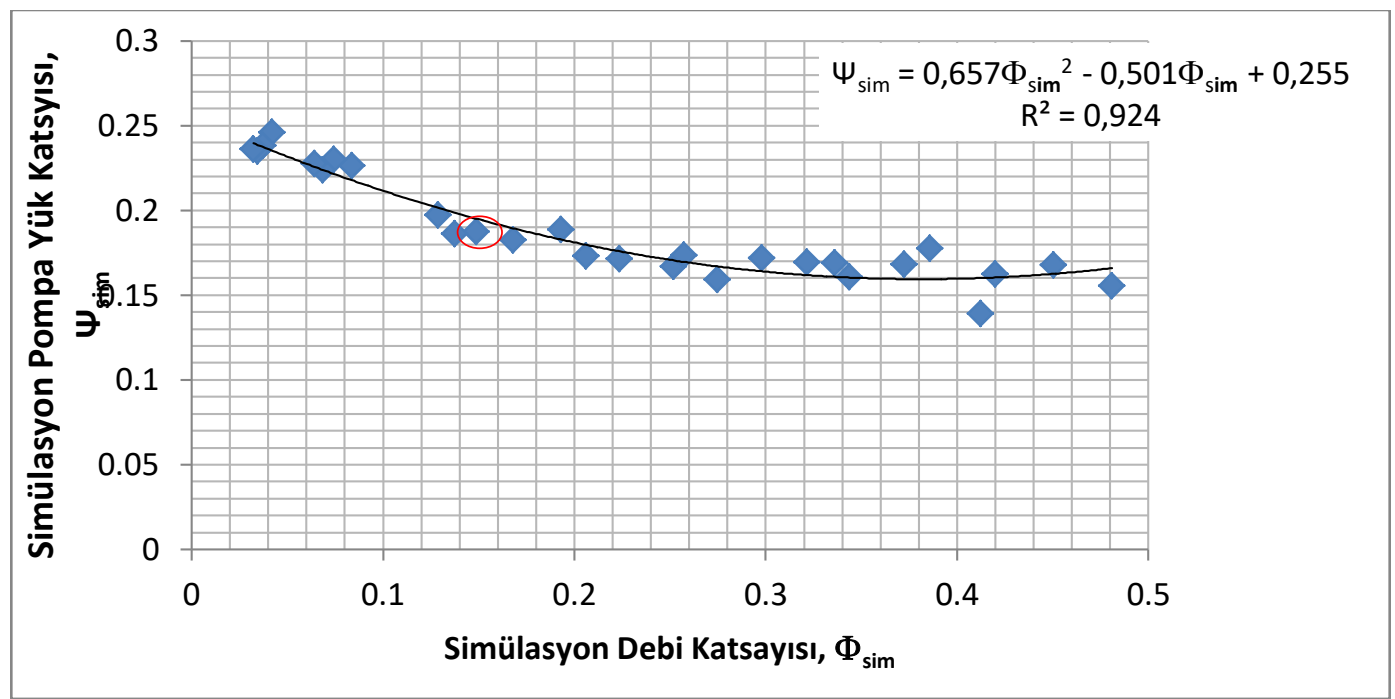

Şekil 7. Boyutsuz parametrelere göre su için HAD simülasyonu performans eğrileri Figure 7. CFD performance curves for water according to dimensionless parameters 
Kan benzeri akışkan için çeşitli pompa devir sayıları için HAD simülasyonu kullanılarak oluşturulan boyutsuz debi-basınç grafiği Şekil 8'de gösterilmiştir. Bu çalışmada kullanılan pompaya ait doğrultucu, çark ve difüzörün kanat ucu çapları yaklaşık aynıdır; fakat bu elemanların göbek çapları akış önünde

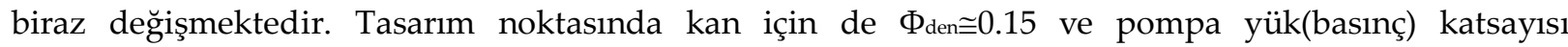
$\psi_{\text {den } \cong 0.175}$ dir. Benzer sonuçlar Throckmorton ve diğ.(2007) tarafından yapılan çalışmada da elde edilmiştir. Ancak bu pompanın geometrisi biraz farklıdır; akış yönünde eksenel çarkın çapı artmaktadır, difüzörün çapı ise azalmaktadır.

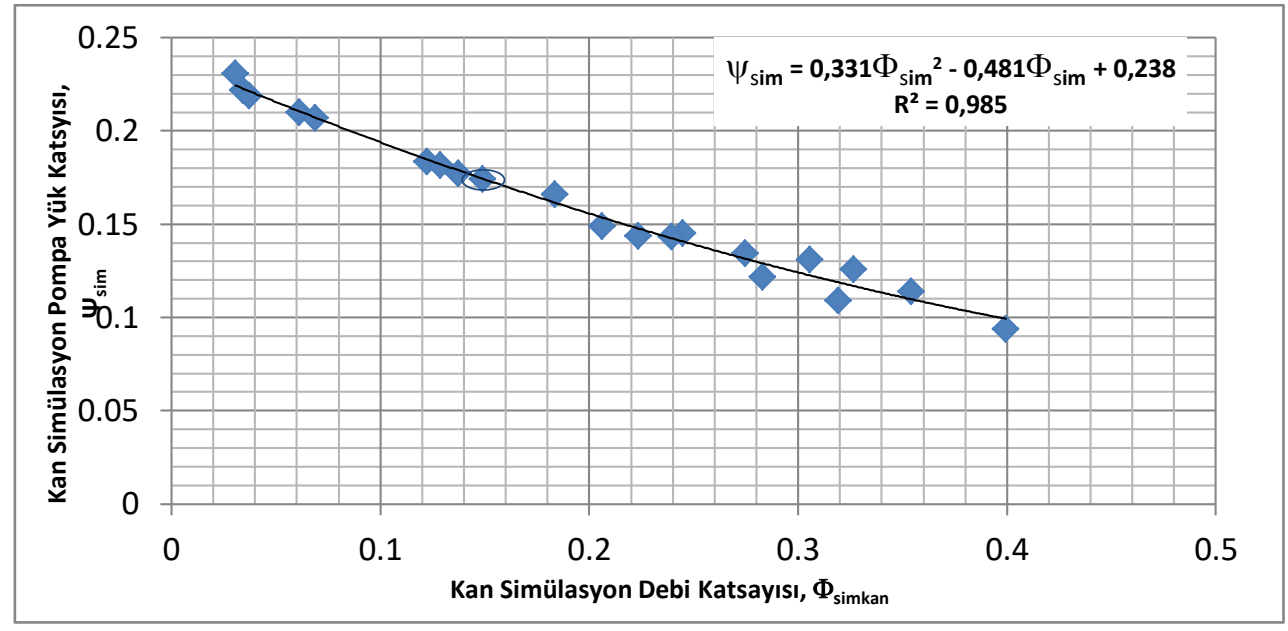

Şekil 8. Boyutsuz parametrelere göre kan benzeri akışkan için HAD simülasyonu performans eğrileri Figure 8. CFD performance curves for blood-like fluid according to dimensionless parameters

HAD simülasyonunda kullanılan akışkanın yoğunluk ve viskozitesi değiştirilerek akışkan kana benzetildi ve tasarım dönme sayısı olan 11750 dev/dak dönme hızında analizler tekrarlandı. Akışkanın yoğunluğu $1050 \mathrm{~kg} / \mathrm{m}^{3}$ ve viskozitesi 0,0035 Pa.s olacak şekilde ayarlandı.

HAD simülasyon sonuçlarına göre elde edilen $H=f(Q)$ performansının su ile karşılaştırılması Şekil 9'da verilmiştir. Kan benzeri akışkan ve su ile yapılan analizlerin sonuçlarının benzerlik gösterdiği tespit edilmiştir. Tasarım debisi $2 \mathrm{~L} /$ dak için pompa yükü yaklaşı $80 \mathrm{mmHg}$ 'dir. $\Phi_{\text {den }} \cong 015$ ve pompa yük( basınç) katsayısı $\psi$ den $\cong 0.175$ 'dir. Throcmorton ve diğ. (2007) tarafından yapılan deneysel ve simülasyon çalışmasında çark çapı $14 \mathrm{~mm}$ olan bir kalp destek pompasında $\mathrm{n}=9000 \mathrm{dev} / \mathrm{dak}$ dönme sayısı ve $\mathrm{Q}=2$

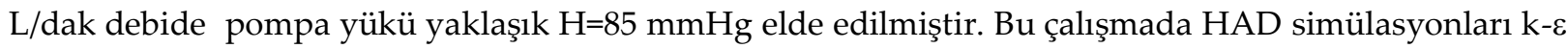
türbülans modeli kullanılarak yapılmıştır. Çalışmanın deney kısmında eksenel akışlı pompa, bu çalışmadaki gibi, dıştan bir elektrik motoruyla tahrik edilmiştir.

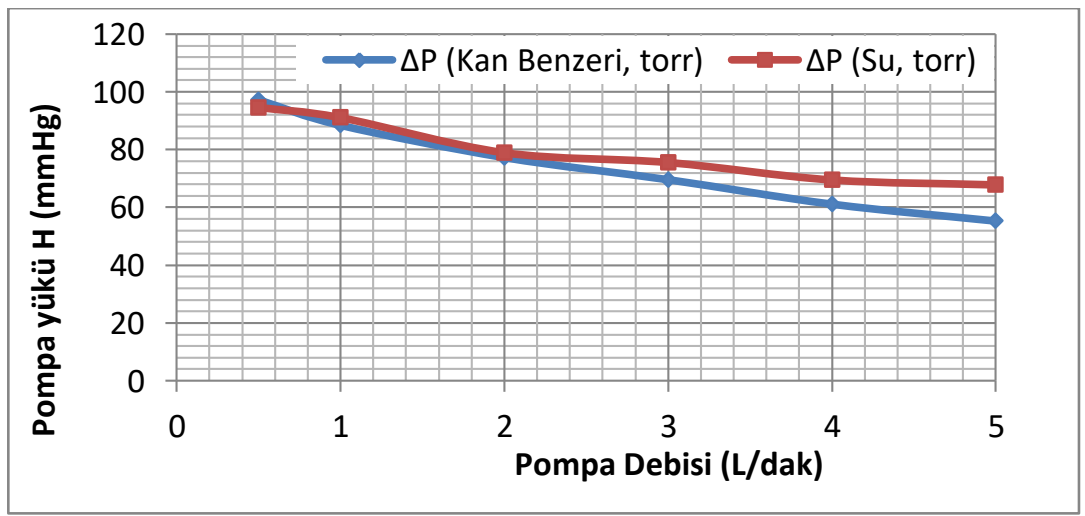

Şekil 9. Kan benzeri akışkan ve su için performans karşılaştırma grafiği

Figure 9. Performance comparison chart for blood-like fluid and water 
Schüle ve diğ. (2016) yaptığı benzer bir çalışmada çark çapı $12 \mathrm{~mm}$ olan bir eksenel akışlı kalp destek pompasında $\mathrm{n}=9000 \mathrm{dev} /$ dak' $^{\prime}$ da $\mathrm{Q}=2 \mathrm{~L} /$ dak debide basınç yaklaşık $80 \mathrm{mmHg}$ olarak elde edilmiştir. $\mathrm{Bu}$ çalışmada değişken göbek çaplı ama sabit kanat ucu çaplı pompanın performansı PIV (Particle Image Velocimetry) yöntemi ve deneysel yöntem kullanılarak belirlenmiştir.

Kan benzeri akışkan ile yapılan $11750 \mathrm{dev} /$ dak'daki HAD simülasyonuyla belirlenen, debiye bağlı olarak hidrolik verim $\eta_{h}=f(Q)$ ve pompa gücü $N_{p}=f(Q)$ grafiği Şekil 10' da gösterilmiştir. Bu grafiğe göre verim, santrifüj ve karışık akışlı pompalarda olduğu debi artışıyla birlikte artmaktadır. Ancak pompa gücü, diğer rotodinamik pompalardan farklı olarak debi arttıkça genellikle azalma göstermektedir. 0.5-5 L/dak debi aralığında pompa gücü yaklaşık olarak 4.5-5.3 W arasında değişmektedir. Bu debi aralığında verim ise \%2-13,27 arasında değişmektedir.

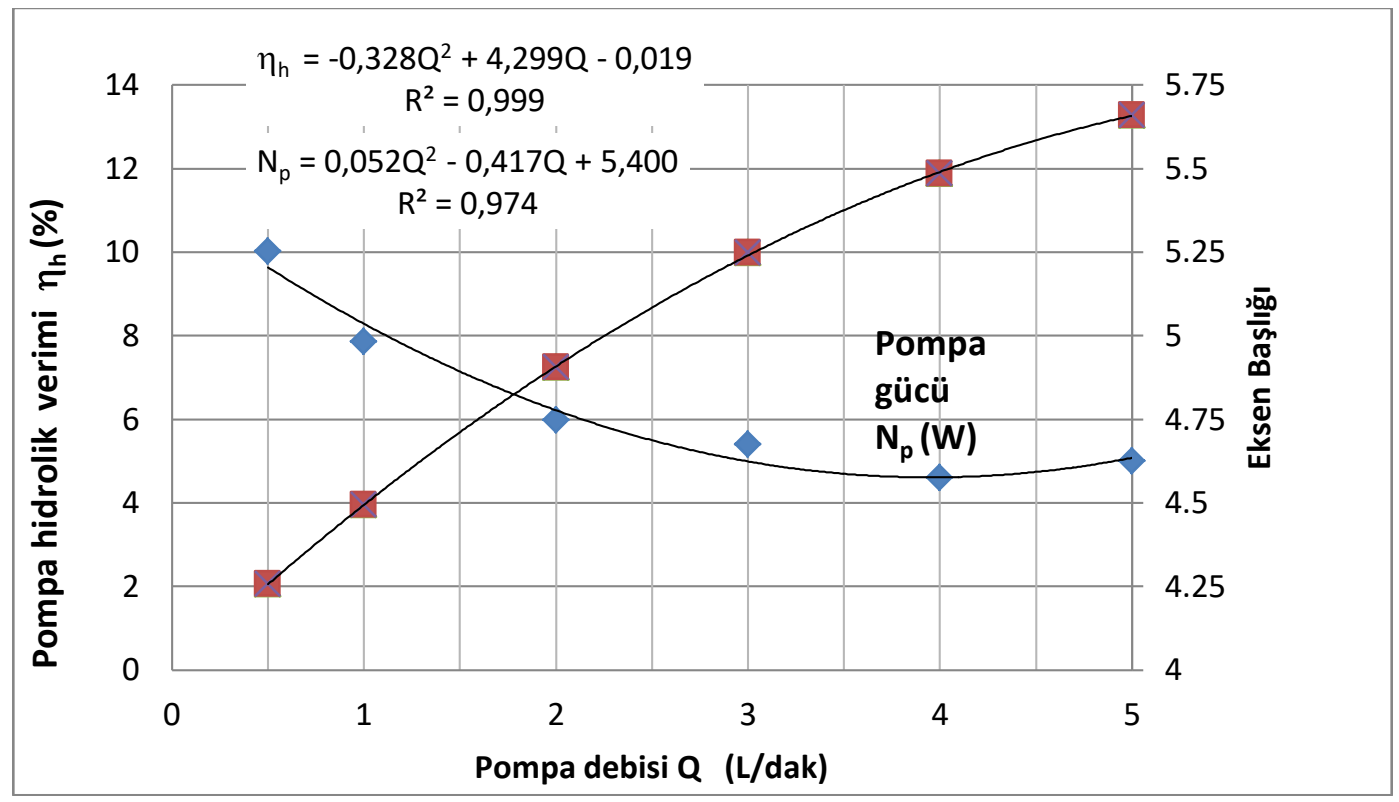

Şekil 10. Kan benzeri akışkan için pompa güç ve verim grafiği Figure 10. Pump power and efficiency graph for blood-like fluid

Kan benzeri akışkan kullanılarak yapılan sayısal analizler sonucunda; $n=11750 \mathrm{dev} / \mathrm{dak}, \mathrm{Q}=2 \mathrm{~L} / \mathrm{dak}$ ve $\mathrm{H}=80 \mathrm{mmHg}$ için elde edilen akış çizgileri Şekil 11'de gösterilmiştir. Akış pompaya doğrultucu sayesinde eksenel yönde girmektedir. Akışın çizgisel hızının en çok yükseldiği bölgenin çark çıkışı olduğu görülmüştür. Pompa çıkışından sonra hidrolik kayıpları azaltmak için çarktan sonra yerleştirilen difüzör akışı hem yavaşlatmaktadır hem de dönmesi almaktadır. Akışta biraz dönme görülse de, pompadan sonraki basma borusunda akışkanın nerdeyse eksenel yönde hareket ettiği görülmektedir. 


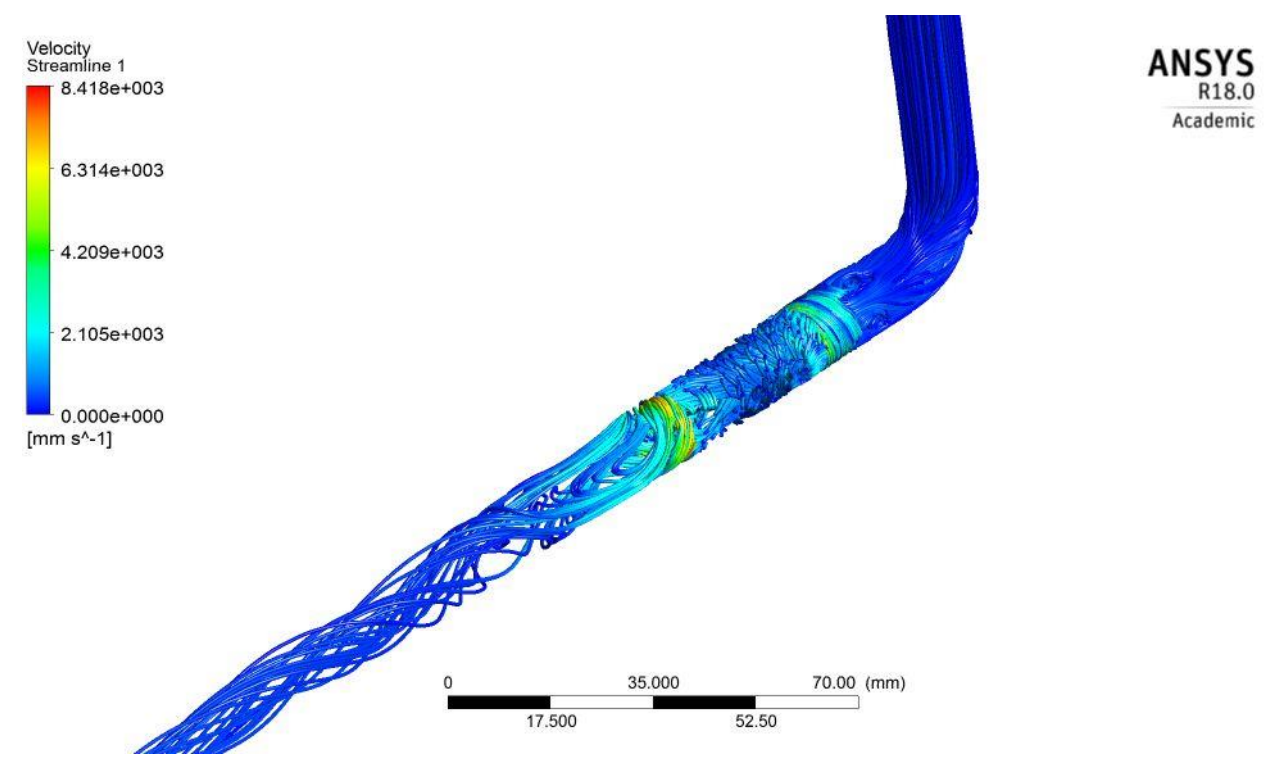

Şekil 11. Kan benzeri akışkan için akış çizgileri Figure 11. Flow lines of blood-like fluid

Kan pompalarının tasarımındaki en önemli parametrelerden biri de pompa içi kayma gerilmeleridir. Kan hücrelerinin dayanabileceği maksimum kayma gerilmesi için genel olarak $400 \mathrm{~Pa}$ seviyesindeki gerilmeler sınır olarak kabul edilmektedir ( $\mathrm{Lu}$ ve diğ., 2001). Sayısal analizlerle $11750 \mathrm{dev} / \mathrm{dak}$ ve kan değerleri girilerek yapılan testlerle belirlenen, pompa içinde meydana gelen kayma gerilmesinin önemli olduğu bölgeler Şekil 12' de açlk tonlu renklerle gösterilmiştir. Kayma gerilmelerinin limitin üzerine çıktığı bölgeler akışın ani olarak yön değiştirdiği çark girişi ve doğrultucu girişleridir. Kayma gerilmesinin en yüksek olduğu noktanın 2664 Pa ile doğrultucu kanatlarının giriş ucu olduğu görüldü.

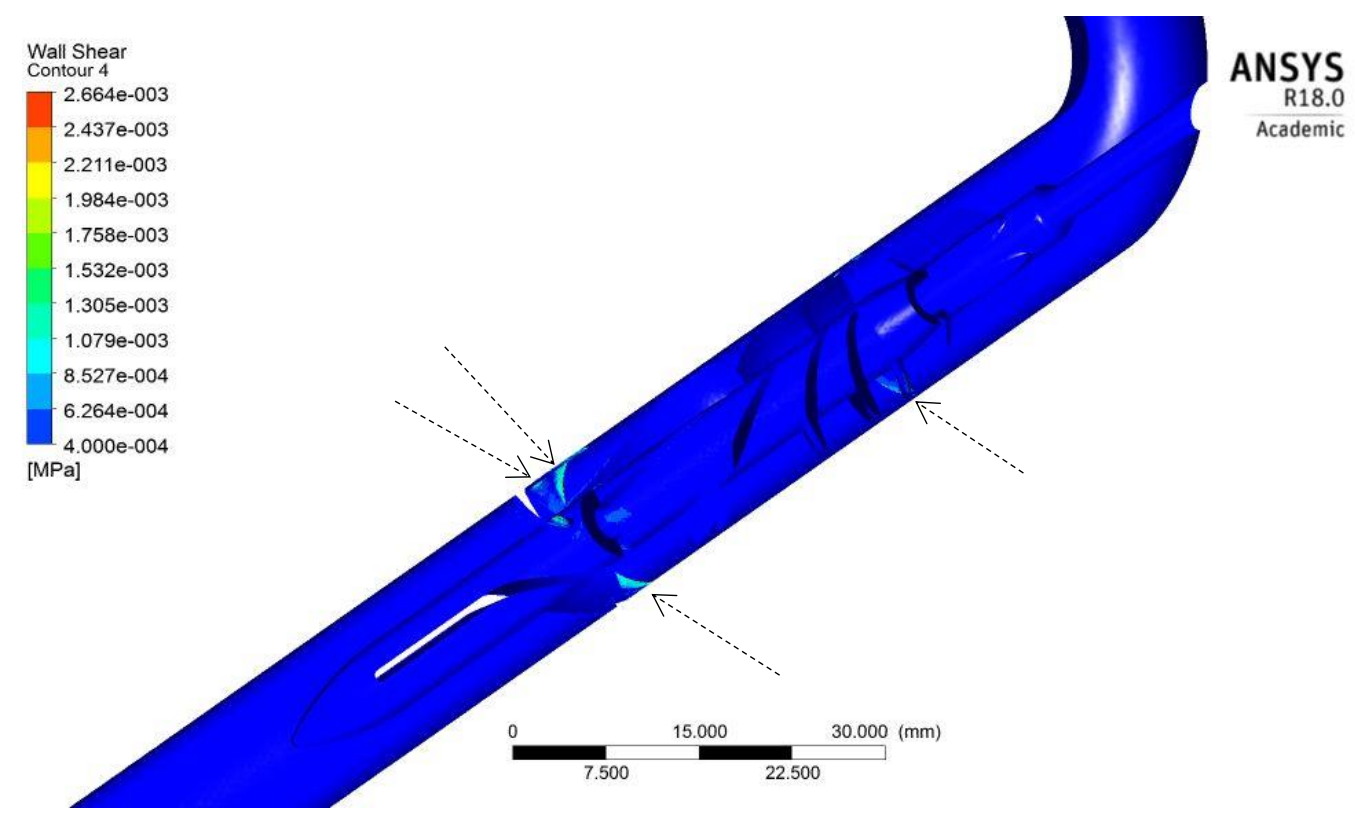

Şekil 12. Kan benzeri akışkan için kayma gerilmeleri Figure 12. Shear stresses for blood-like fluid 
Pompanın radyal simetri düzlemindeki hız vektörlerinin projeksiyonları Şekil 13'de verilmiştir. Doğrultucu girişinde (Kayma gerilmelerinin en çok yükseldiği bölge) akıştaki yön değiştirmeler ve girdaplar görülmektedir.

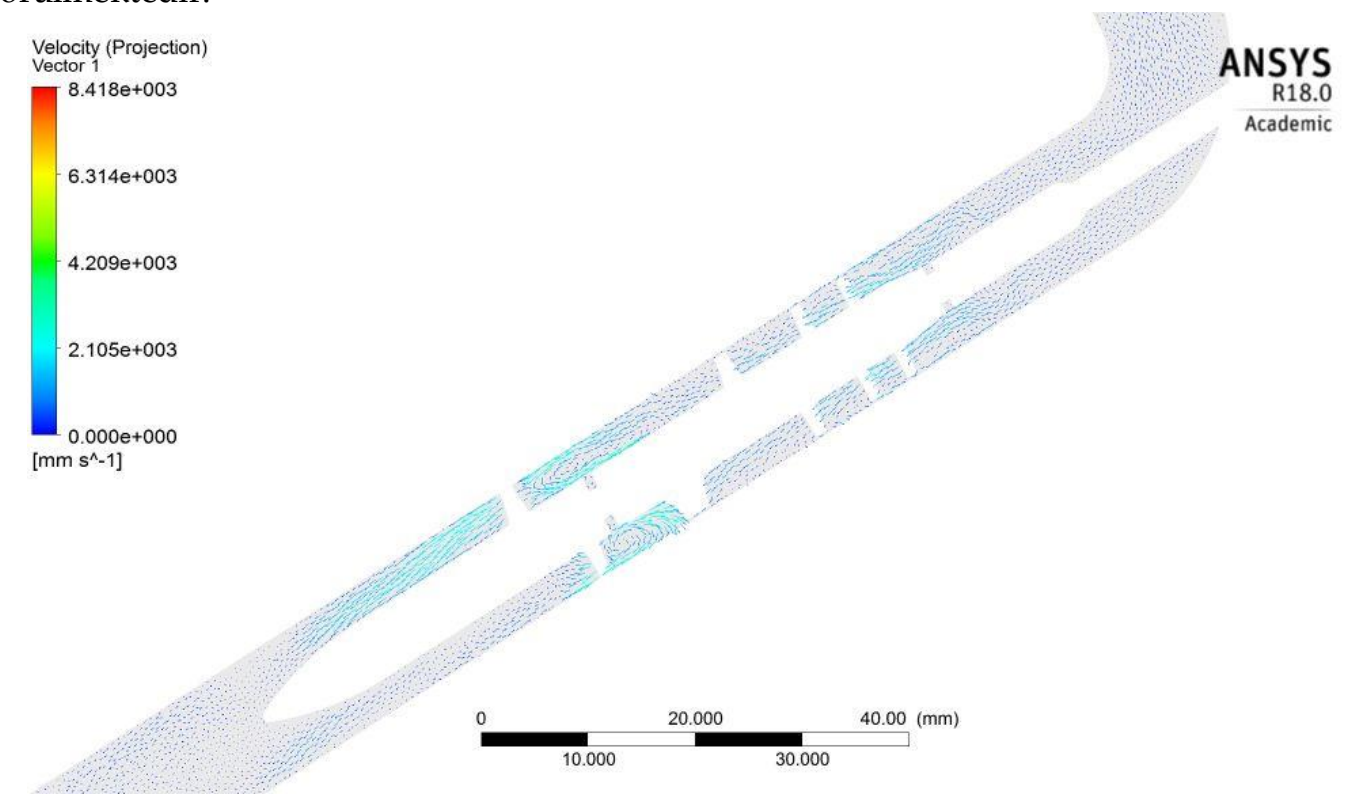

Şekil 13. Pompa radyal simetri düzlemindeki hız vektörleri

Figure 13. Velocity vectors in the pump radial symmetry plane

\section{ARAŞTIRMA SONUÇLARI (RESEARCH RESULTS)}

Bu çalışmada pompa tasarım programları ile tasarlanan pediatrik bir kalp destek pompasının HAD performansı, yeni bir geçiş türbülans modeli olan $\mathrm{k}_{\mathrm{T}}-\mathrm{kL}_{\mathrm{L}}-\mathrm{W}$ modeli kullanılarak belirlenmiş ve HAD simülasyon sonuçları deneysel olarak doğrulanmıştır. Çok farklı pompa hızları ve debilerinde yapılan testler sonucunda boyutsuz parametrelere bağlı olarak pompa performansı belirlenmiştir. Test verileriyle pompa debisi $(\mathrm{Q})$ ve pompa yükü $(\mathrm{H})$ arasındaki boyutsuz bağıntı $\psi=\mathrm{f}(\Phi)$ elde edilmiştir. Bu bağıntının korelasyon katsayısı $\mathrm{R}^{2}, \% 92$ 'den daha büyüktür.

Üzerinde çalışılan çocuk kalp destek pompasının HAD simülasyonuyla tasarım noktasındaki boyutlu ve boyutsuz performans parametreleri, literatürdeki benzer pompaların deneysel ve simülasyonla belirlenen parametreleriyle karşılaştırılmıştır. Boyutsuz debi katsayısı esas alınarak yapılan karşılaştırmada basınç katsayılarının birbirine çok yakın olduğu görülmüştür. Bu sonuçla birlikte, HAD ile pompa tasarlayıp performansını belirleyip, performansına bakılarak amaca uygun olarak tasarımın modifiye edilmesi açısından HAD yazılımlarının maliyet ve zaman faktörleri dikkate alındığında faydası net bir şekilde ortaya çıkmaktadır.

Doğrulama deneyleriyle HAD simülasyonuyla elde edilen sonuçlar arasında iyi bir uyum gözlendi. $\mathrm{Bu}$ uyum neticesinde, tasarım aşamasında karşılaşılabilecek sorunların giderilmesi ve daha iyi performansa sahip kalp destek pompaları geliştirilmesi için HAD simülasyonlarının güvenilir olduğu söylenebilir.

HAD simülasyonlarına ait görüntüsel sonuçlara baktığımız zaman pompa içinde kayma gerilmeleri, çark çıkışı ile doğrultucu girişi arasında ve akışın ani yön değişimi gösterdiği bölgelerde artmaktadır. Yüksek kayma gerilmelerinden kaçınmak için bu tip bölgelere yoğunlaşmak gerektiği anlaşıldı. Günümüzdeki çalışmalar, ağırlıklı olarak bu bölgelerde geometri düzeltmeleriyle kayma gerilmesi değerlerinin istenen limitlerin altına çekilmesi üzerinedir.

$\mathrm{Bu}$ mini kalp destek pompalarının monoblok olarak tasarlanması ve pompa içindeki kayma gerilmelerinin uygun seviyeye getirilmesi için çalışmalar sürdürülmektedir. 


\section{TEŞEKKÜRLER (ACKNOWLEDGEMENT)}

Bu çalışma Selçuk Üniversitesi BAP Koordinatörlüğü tarafından BAP-15201109 numaralı proje kapsamında desteklenmiştir.

\section{SEMBOLLER (NOTATION)}

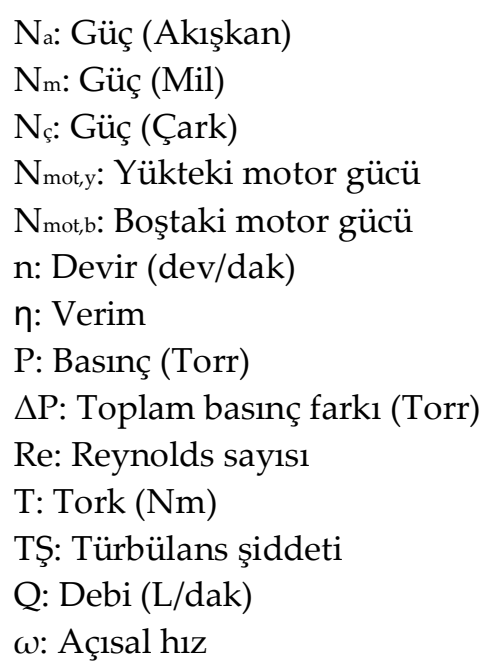

\section{İNDİSLER (INDICES)}
a: Akışkan
b: Boşta
ç: Çıkış
g: Giriş
h: Hidrolik
m: Mil
p: Pompa

\section{KAYNAKLAR (RESOURCES)}

Aka, İ.B., Dadgar, S., Sezer, M.E., Kadıpaşaoğlu, A.K., "Bir Eksenel Akışlı Sol Ventrikül Destek Pompasının (SVDP) Fiziki Performans Testleri İçin Platform Tasarımı" , 14. Tip Teknolojileri Ulusal Kongresi, Kapadokya, Nevşehir, 25-27 Eylül 2014.

Baldwin, J. T., Borovetz, H. S., Duncan, B. W., Gartner, M. J., Jarvik, R. K., Weiss, W. J., 2011, "The National Heart, Lung, and Blood İnstitute Pediatric Circulatory Support Program: A Summary of the 5-Year Experience", Circulation, Vol. 123 (11), pp. 1233-1240.

B Clark, J., B Pauliks, L., L Myers, J. ve Undar, A., 2011, "Mechanical Circulatory Support for End-Stage Heart Failure in Repaired and Palliated Congenital Heart Disease", Current Cardiology Reviews, Vol. 7 (2), pp. 102-109.

Demir, O., Biyikli, E., Lazoglu, I., Kucukaksu, S., 2011, "Design of a Centrifugal Blood Pump: Heart Turcica Centrifugal", Artificial Organs, Vol. 35 (7), pp. 720-725.

Fluent, A., 2017, 18.0 ANSYS Fluent theory guide 18.0, Ansys Inc.

Fürst, J., Straka, P., Př́hoda, J., Šimurda, D., 2013, "Comparison of Several Models of the Laminar/Turbulent Transition", EPJ Web of Conferences, 01032. 
Kafagy, D. H., Dwyer, T. W., McKenna, K. L., Mulles, J. P., Chopski, S. G., Moskowitz, W. B., Throckmorton, A. L., 2015, "Design of Axial Blood Pumps for Patients with Dysfunctional Fontan Physiology: Computational Studies and Performance Testing", Artificial organs, Vol. 39 (1), pp. 34-42.

Lu, P., Lai, H., Liu, J., 2001, "A Reevaluation and Discussion on the Threshold Limit for Hemolysis in a turbulent Shear Flow", Journal of Biomechanics, Vol. 34 (10), pp. 1361-1364.

Reul, H. M., Akdis, M., 2000, "Blood Pumps for Circulatory Support", Perfusion, Vol. 15 (4), pp. 295-311.

Sağlık Bakanlığı, 2015, Türkiye Kalp ve Damar Hastalıkları Önleme ve Kontrol Programı, Ankara p.

Schüle, C. Y., Thamsen, B., Blümel, B., Lommel, M., Karakaya, T., Paschereit, C. O., Affeld, K., Kertzscher, U., 2016, "Experimental and Numerical İnvestigation of an Axial Rotary Blood Pump", Artificial Organs, Vol. 40 (11).

Throckmorton, A. L., Untaroiu, A., Allaire, P. E., Wood, H. G., Lim, D. S., McCulloch, M. A., Olsen, D. B., 2007, "Numerical Design and Experimental Hydraulic Testing of an Axial Flow Ventricular Assist Device for Infants and Children", Asaio Journal, Vol. 53 (6), pp. 754-761.

Throckmorton, A. L., Untaroiu, A., 2008, "CFD Analysis of a Mag-Lev Ventricular Assist Device for Infants and Children: Fourth Generation Design", Asaio Journal, Vol. 54 (4), pp. 423-431.

Walters, D. K., Leylek, J. H., 2004, "A New Model for Boundary Layer Transition Using a Single-Point RANS Approach", Journal of Turbomachinery, Vol. 126 (1), pp. 193-202.

Walters, D. K., Cokljat, D., 2008, "A Three-Equation Eddy-Viscosity Model for Reynolds-Averaged Navier-Stokes Simulations of Transitional Flow", Journal of fluids engineering, Vol. 130 (12), 121401.

Warnes, C. A., 2005, "The adult with congenital Heart Disease: Born to be bad?", Journal of the American College of Cardiology, Vol. 46 (1), pp. 1-8.

Wu, J., Antaki, J. F., Verkaik, J., Snyder, S., Ricci, M., 2012, "Computational Fluid Dynamics-Based Design Optimization for an Implantable Miniature Maglev Pediatric Ventricular Assist Device", Journal of fluids engineering, Vol. 134 (4), 041101.

Wu, Z., Gottlieb, R., Burgreen, G., Holmes, J., Borzelleca, D., Kameneva, M., Griffith, B., Antaki, J., 2001, "Investigation of Fluid Dynamics within A Miniature Mixed Flow Blood Pump", Experiments in Fluids, Vol. 31 (6), pp. 615-629. 